\title{
Corrosion Inhibition of Aqueous Extract of Senna Auriculata Leaves on Carbon Steel in Hydrochloric Acid Medium
}

\author{
K. HEMA $^{1,2}$, B. R.VENKATRAMAN ${ }^{2 *}$ and A. SUBRAMANIA ${ }^{3}$ \\ ${ }^{1}$ Department of Chemistry, Saveetha School of Engineering, Saveetha University, \\ Chennai-602 105, Tamil Nadu, India \\ ${ }^{2}$ Post Graduate and Research Department of Chemistry, \\ Periyar E. V. R. College (Autonomous), Tiruchirappalli-620023, Tamil Nadu, India \\ ${ }^{3}$ Centre for Nanoscience and Technology, \\ Pondicherry University, Puducherry-605014, India \\ brvenkatraman@yahoo.com
}

Received 16 July 2015 / Accepted 24 July 2015

\begin{abstract}
The performance of Senna auriculata leaves (SCL) extract as a corrosion inhibitor for carbon steel in $1 \mathrm{~N} \mathrm{HCl}$ was thoroughly investigated by chemical and electrochemical methods. The inhibition efficiency obtained by both these methods has good agreement with each other. The effects of temperature and immersion time on carbon steel in $1 \mathrm{~N} \mathrm{HCl}$ were also studied. The maximum inhibition efficiency of $75.65 \%$ was obtained at the best concentration of 800 ppm of SCL extract. The polarization studies revealed that the inhibition action of SCL extract was under mixed control. The free energy of adsorption and the influence of temperature on the adsorption of SCL extract on carbon steel have also been reported. The adsorption of SCL extract on the surface of carbon steel was found to obey the Langmuir adsorption isotherm. The mechanism of inhibition was confirmed by kinetic and thermodynamic parameters obtained from $303 \mathrm{~K}$ to $363 \mathrm{~K}$ temperatures using weight loss method. The metallurgical microscope results established the formation of a protective layer on the carbon steel surface.
\end{abstract}

Keywords: Corrosion inhibitors, Senna auriculata extract, Carbon steel corrosion, Langmuir adsorption isotherm, Mixed type inhibitor

\section{Introduction}

Automobile and chemical industries, most widely use carbon steel as a constructional material due its excellent mechanical properties and low cost ${ }^{1}$. The main problem concerning carbon steel applications is its relatively low corrosion resistance in acidic solutions ${ }^{2}$. Since hydrochloric acid is mainly used for chemical cleaning, descaling, pickling and oil-well acidizing, it leads to corrosive attack $^{3-4}$. Corrosion causes awful damage to 
metal and alloy structures causing great economic losses and environmental pollution. Due to these harmful effects, corrosion ought to be prevented ${ }^{5}$. Among the several methods of corrosion control and prevention, the use of corrosion inhibitors, is very popular ${ }^{6}$. Most of the efficient inhibitors are organic compounds, but their use is limited because they are expensive and toxic for the environment ${ }^{7}$. This has initiated the search for alternate nontoxic and inexpensive corrosion inhibitors in different parts of plant extract ${ }^{8-10}$. There is a close proximity between the phytochemical compounds present in the plant extract to those of conventional organic inhibitors, which justified the use of plant products as corrosion inhibitors ${ }^{11}$. Scientific corrosion literature has descriptions and lists of numerous plant extracts $^{12-23}$ such as Garcinia mangostana, Vernonia amygdalina, Ficus benghalensis, Canavalia ensiformis, Mangifera indica, Artemisia pallens, Paniala, Murraya koenigii, Stevia rebaudiana, Haloxylon scoparium, Pavetta indica, Aquilaria crassna, exhibit inhibitive properties for carbon steel in acidic solutions.

The present work continues to focus on the application of extract obtained from Senna auriculata leaves (SCL) on the corrosion inhibition of carbon steel in $1 \mathrm{~N} \mathrm{HCl}$, using weight loss, gas evolution, potentiodynamic polarization and AC-impedance studies. From this, a suitable mechanism regarding the mode of inhibition was also proposed. Surface examination of the carbon steel in the absence and presence of inhibitor was made to confirm the protective layer on the surface of carbon steel.

\section{Experimental}

$\mathrm{HCl}(\mathrm{AR})$ and double distilled water were used throughout the studies for preparing the aggressive solutions $(1 \mathrm{~N} \mathrm{HCl})$. The composition of the carbon steel sample used in this experiment was (wt\%) is $0.18 \mathrm{C}, 0.30 \mathrm{Mn}, 0.15 \mathrm{Si}, 0.02 \mathrm{~S}, 0.02 \mathrm{P}$ and the balance being Fe. The rectangular shape carbon steel of dimension $4.5 \times 2 \times 0.2 \mathrm{~cm}$ containing a small hole of about $2 \mathrm{~mm}$ diameter near the upper edge was employed for weight loss and gasometric studies. The specimens used were polished mechanically followed by different grades of emery papers and then degreased with acetone. A cylindrical carbon steel specimens with an exposed area of $1 \mathrm{~cm}^{2}$ (remaining area covered with Teflon holder) were used for electrochemical studies.

\section{Preparation of senna auriculata leaves (SCL) extract}

Senna auriculata is a legume tree in the subfamily of Caesalpinioideae. It is commonly known by its local names ranawara or avaram. It occurs in the dry regions of India and Sri Lanka. It is common along the sea coast and the dry zone in Sri Lanka ${ }^{24-26}$. Leaves of Senna auriculata (Aavaram) were cleaned and cut into small pieces. They were dried in an air oven at $70{ }^{\circ} \mathrm{C}$ for $2 \mathrm{~h}$. The dried leaves were pulverized and make it well into powder. $10 \mathrm{~g}$ of the leaf powder was refluxed in $100 \mathrm{~mL}$ of distilled water for an hour. The refluxed solution was filtered through Whatmann No.1 filter paper and then the filtrates were heated on a water bath to evaporate the moisture content fully to get the dried compound ${ }^{27}$. Corrosion test solutions range from $200 \mathrm{ppm}$ to $800 \mathrm{ppm}$ were prepared by dissolving specified amount of dried SCL extract in $1 \mathrm{~N} \mathrm{HCl}$ solution and used for corrosion study.

\section{Weight loss studies}

Previously polished and degreased specimens of size $4.5 \times 2 \times 0.2$ were used for weight loss studies. Already weighed carbon steel specimens were separately immersed in $100 \mathrm{~mL}$ of $1 \mathrm{~N} \mathrm{HCl}$ solutions containing 200, 400, 600 and $800 \mathrm{ppm}$ of the SCL extract for $3 \mathrm{~h}$. After the specified time, the carbon steel specimens were taken out from the acid solution 
and then washed immediately with double distilled water, dried and re-weighed. Duplicate tests were also conducted for each experiment. The same experiment was carried out at four different temperatures of $303,323,343$ and $363 \mathrm{~K}$. From the measured weight loss data, the corrosion rate (mmpy) and the inhibition efficiency (IE) were calculated using the equation:

\section{Corrosion rate $(\mathrm{mmpy})=\mathrm{kW} / \mathrm{ATD}$}

Where $\mathrm{k}=8.76 \times 104$ (constant), $\mathrm{W}=$ weight loss in $\mathrm{g}, \mathrm{A}=$ area in square $\mathrm{cm}, \mathrm{T}=$ time in hours and $\mathrm{D}=$ density in $\mathrm{g} /$ cu.cm

$$
\text { Inhibition Efficiency }(\%)=\mathrm{W}_{\mathrm{B}}-\mathrm{W}_{\mathrm{I}} / \mathrm{W}_{\mathrm{B}} \times 100
$$

Where $\mathrm{W}_{\mathrm{B}}$ and $\mathrm{W}_{\mathrm{I}}$ are weight loss per unit time in the absence and presence of the extract in $1 \mathrm{~N} \mathrm{HCl}$ solution.

Weight loss measurements were performed at a different immersion time from 3 hours to 24 hours at the best concentration of $800 \mathrm{ppm}$ of SCL extract at $30^{\circ} \mathrm{C}$. From the initial and final weight of the specimen, the weight loss of the specimen was calculated and the inhibitor efficiency at different immersion time was also calculated.

The degree of surface coverage $(\theta)$ was calculated from the weight loss measurement results using the following formula ${ }^{28}$ :

$$
\text { Surface coverage }(\theta)=\frac{W_{B}-W_{1}}{W_{B}}
$$

Where $\mathrm{W}_{\mathrm{B}}$ is the weight loss in the absence of the SCL extract, $\mathrm{W}_{\mathrm{I}}$ is the weight loss in the presence of the SCL extract in $1 \mathrm{~N} \mathrm{HCl}$ solution. From these data, a suitable isotherm were fitted graphically.

\section{Gasometric studies}

Comparing weight loss studies, the gasometric studies will give more accuracy result in which the SCL extract does not react with hydrogen gas as well as the hydrogen penetration into the metal is small compared to the total volume of hydrogen gas. The design of the studies is described elsewhere ${ }^{29}$. The carbon steel specimen was suspended from the hook of the glass stopper and was introduced into the sample cell containing $100 \mathrm{~mL}$ of $1 \mathrm{~N} \mathrm{HCl}$ solution. At constant atmospheric pressure, $30^{\circ} \mathrm{C}$ temperature was maintained constant throughout the experiment. The volume of hydrogen gas liberated will be measured for a period of three hours in all the cases. From the volume of hydrogen gas liberated, the inhibition efficiency was calculated using the formula:

$$
\text { Inhibition efficiency }(\%)=\frac{\mathrm{V}_{0}-\mathrm{V}_{1}}{\mathrm{~V}_{1}} \times 100
$$

Where $\mathrm{V}_{0}$ is the volume of hydrogen evolved in the absence of SCL extract and $\mathrm{V}_{\mathrm{I}}$ is the volume of hydrogen evolved in the presence of SCL extract in $1 \mathrm{~N} \mathrm{HCl}$ solution.

\section{Electrochemical polarization studies}

The electrochemical measurements were performed in a conventional three-electrode assembly containing a cylindrical carbon steel specimen with an exposed area of $1 \mathrm{~cm}^{2}$ as working electrode (WE), a platinum foil of surface area $2 \mathrm{~cm}^{2}$ as counter electrode and a saturated calomel electrode (SCE) provided with a Luggin capillary as a reference electrode. They were immersed in $1 \mathrm{~N} \mathrm{HCl}$ solution until a steady-state open circuit potential (OCP) was obtained. The $\mathrm{HCl}$ solution was degassed with ultrapure nitrogen bubbling to avoid any reactions with dissolved oxygen. Tafel polarization measurements were made for a potential range of $-200 \mathrm{mV}$ to $+200 \mathrm{mV}$ with respect to OCP at a scan rate of $1 \mathrm{mV} / \mathrm{s}$. 
From the electrochemical studies, corrosion potential and corrosion current were calculated. The inhibitor efficiency was calculated using the formula ${ }^{30}$ :

$$
\operatorname{IE}(\%)=\frac{\mathrm{I}_{\text {corr }}-\mathrm{I}^{*}{ }_{\text {corr }}}{\mathrm{I}_{\text {corr }}} \times 100
$$

Where $\mathrm{I}_{\text {corr }}$ and $\mathrm{I}^{*}{ }_{\text {corr }}$ are corrosion current in the absence and presence of the SCL extract in $1 \mathrm{~N} \mathrm{HCl}$ solution.

\section{Electrochemical impedance studies}

Electrochemical impedance studies (EIS) has been widely used in investigating the corrosion inhibition process. Since, it provides more information on both the resistive and capacitive behaviors at the metal/solution interface. The corrosion behavior of carbon steel in $1 \mathrm{~N} \mathrm{HCl}$ solution in the absence and presence of the extract was investigated by using an electrochemical analyzer (BioLogic-VSP, France). The impedance measurements were carried at the open circuit potential in the frequency range of $100 \mathrm{kHz}$ to $1 \mathrm{mHz}$. A plot of Z' vs. Z" were made. From the Nyquist plot, the charge transfer resistance $\left(R_{t}\right)$ was calculated. The double layer capacitance $\left(C_{d l}\right)$ was calculated using the following equation ${ }^{31}$ :

$$
C_{\mathrm{dl}}=\frac{1}{2 \pi f_{\max } R_{t}}
$$

Where $R$ : is charge transfer resistance and $C_{d l}$ is the double layer capacitance. The experiments were carried out in the absence and presence of the best concentrations of SCL extract in $1 \mathrm{~N} \mathrm{HCl}$ solution. The percentage of inhibition efficiency was calculated using the equation $^{32}$ :

$$
\operatorname{IE}(\%)=\frac{\mathrm{R}_{\mathrm{t}}^{*}{ }^{*} \mathrm{R}_{\mathrm{t}}}{\mathrm{R}_{\mathrm{t}}^{*}} \times 100
$$

Where $\mathrm{R}_{\mathrm{t}}{ }^{*}$ and $\mathrm{R}_{\mathrm{t}}$ are the charge transfer resistance in the presence and absence of SCL extract in $1 \mathrm{~N} \mathrm{HCl}$ solution.

\section{Surface morphological studies}

The carbon steel specimens were immersed in $1 \mathrm{~N} \mathrm{HCl}$ in the absence and presence of the best concentration of the SCL extract for 3 hours at $30{ }^{\circ} \mathrm{C}$. After 3 hours, the specimens were taken out, dried and kept in desiccators. The protective film formed on the surface of carbon steel was confirmed by metallurgical microscope studies with the magnification of $1000 x$.

\section{Results and Discussion}

\section{Weight loss studies}

Weight loss of carbon steel in $1 \mathrm{~N} \mathrm{HCl}$ was determined at $303 \mathrm{~K}$ in the absence and presence of SCL extract concentrations ranging from 200 to $800 \mathrm{ppm}$. The obtained corrosion parameters are depicted in Table 1. It is cleared from the table that the percentage of inhibition efficiency increases with concentration of SCL extract. The decrease in corrosion rate with an increase in concentration of SCL is due to the fact that the surface coverage of metal increases by the adsorption of inhibitor molecules. A maximum inhibition efficiency of $76.1 \%$ is obtained at the concentration of $800 \mathrm{ppm}$ of extract. The increase in corrosion rate with an increase in temperature is due to increase in the rate of desorption of SCL molecules from the carbon steel surface at higher temperature. 
Table 1. Corrosion parameters obtained from weight loss measurements for carbon steel in $1 \mathrm{~N} \mathrm{HCl}$ containing various concentrations of SCL extract

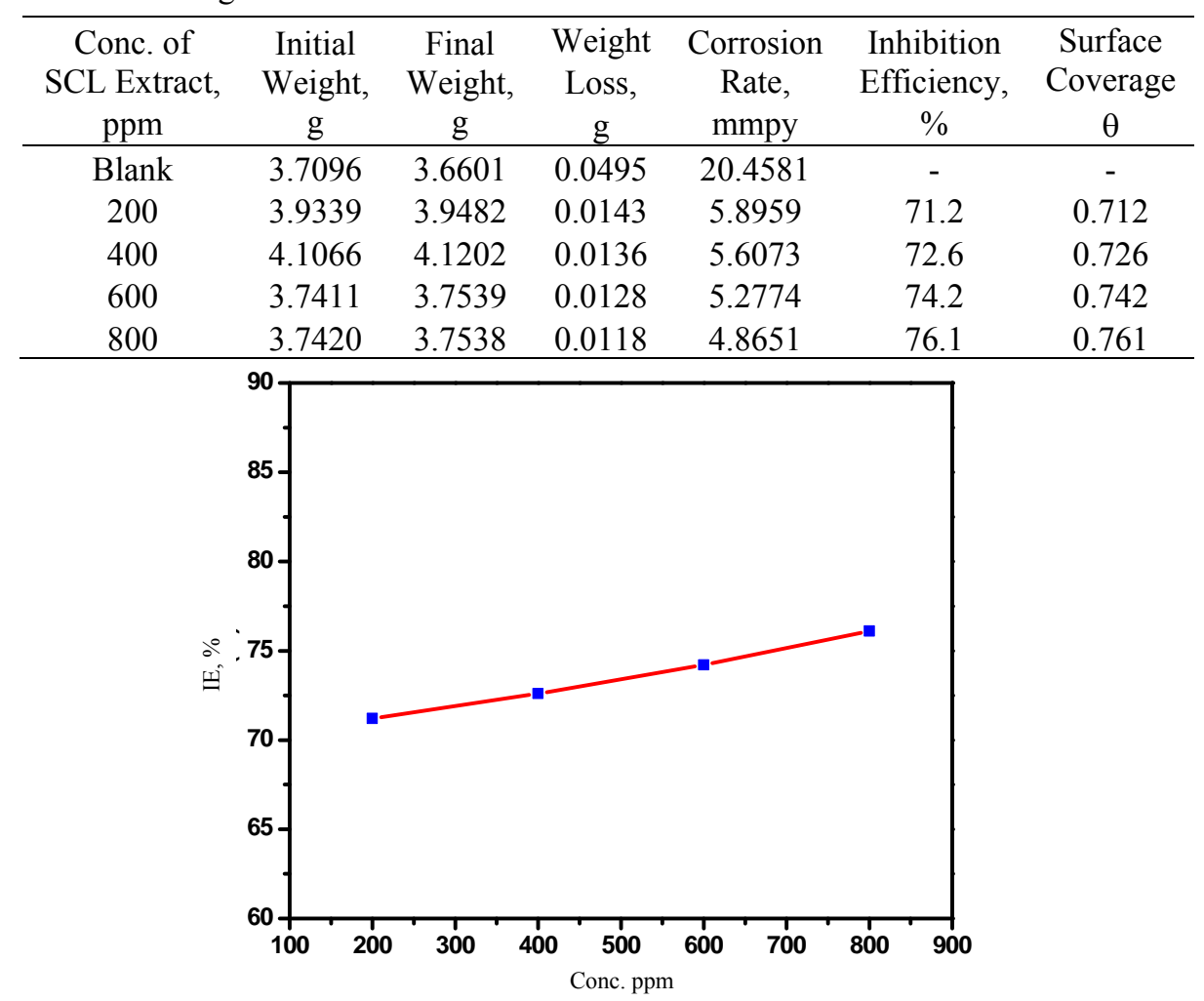

Figure 1. Variation of inhibition efficiency with various concentrations of SCL extract on carbon steel in $1 \mathrm{~N} \mathrm{HCl}$ solution

\section{Effect of immersion time}

The effect of immersion time from 3 hours to 24 hours on inhibition efficiency was studied and depicted in Table 2. The effect of immersion time on percentage inhibition efficiency of carbon steel in $1 \mathrm{~N} \mathrm{HCl}$ at $30{ }^{\circ} \mathrm{C}$ in presence of the best concentration $(800 \mathrm{ppm})$ of SCL extract is shown in Figure 2. The inhibition efficiency was found to decrease from $76.1 \%$ to $73.5 \%$, when immersion time was increased due to desorption of adsorbed SCL extract constituents. Hence, using weight loss method, the minimum inhibition efficiency of $73.5 \%$ was found at $30{ }^{\circ} \mathrm{C}$ for SCL extract which acted as a corrosion inhibitor at the best concentration of $800 \mathrm{ppm}$ for a period of 24 hours.

Table 2. Effect of immersion time on percentage inhibition efficiency of carbon steel in $1 \mathrm{~N}$ $\mathrm{HCl}$ at $30{ }^{\circ} \mathrm{C}$ in presence of the best concentration (800 ppm) of SCL extract

\begin{tabular}{ccccccccc}
\hline \multirow{2}{*}{$\begin{array}{c}\text { Conc. of SCL extract, } \\
\text { ppm }\end{array}$} & \multicolumn{8}{c}{ Timhibition efficiency, $\%$} \\
\cline { 2 - 9 } & 3 & 6 & 9 & 12 & 15 & 18 & $\mathbf{2 1}$ & 24 \\
\hline 800 & $\mathbf{7 6 . 1}$ & 75.8 & 75.4 & 74.9 & 74.4 & 74.1 & 73.8 & 73.5 \\
\hline
\end{tabular}




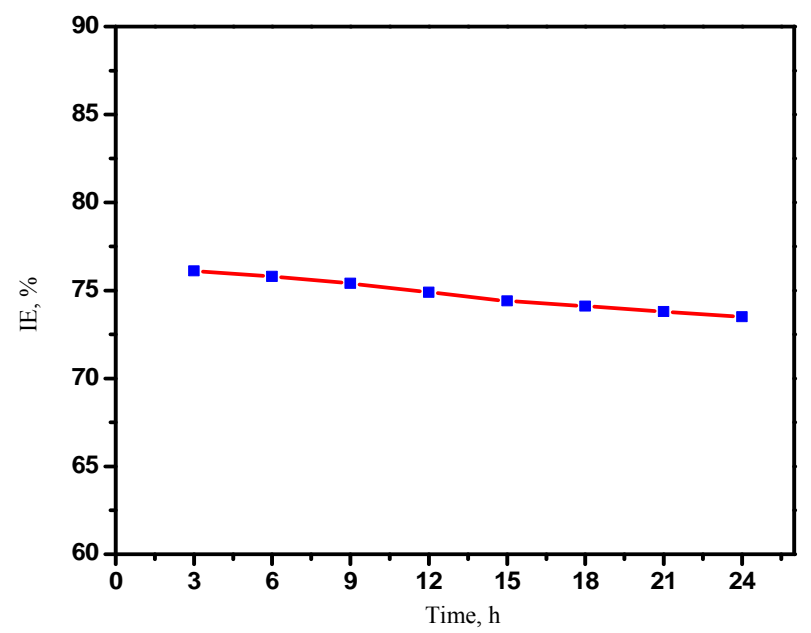

Figure 2. Effect of immersion time on percentage inhibition efficiency of carbon steel in $1 \mathrm{~N} \mathrm{HCl}$ at $30^{\circ} \mathrm{C}$ in presence of the best concentration (800 ppm) of SCL extract

\section{Gasometric studies}

The volume of hydrogen gas evolved is decreased from 7.4 to $1.7 \mathrm{~mL}$ with an increase in the concentration of SCL extract from 200 to $800 \mathrm{ppm}$. The inhibition efficiency increased from 71.4 to $76.4 \%$ is shown in Table 3. Hence, the best concentration of SCL extract was found to be $800 \mathrm{ppm}$. It revealed that SCL extract had the tendency to inhibit carbon steel corrosion in acid medium.

Table 3. Inhibition efficiency obtained from gasometric measurements for carbon steel in $1 \mathrm{~N} \mathrm{HCl}$ containing various concentrations of SCL extract at $30^{\circ} \mathrm{C}$

\begin{tabular}{ccc}
\hline $\begin{array}{c}\text { Conc. of SCL } \\
\text { extract, \% in v/v }\end{array}$ & $\begin{array}{c}\text { Volume of hydrogen } \\
\text { gas evolved, } \mathrm{mL}\end{array}$ & $\begin{array}{c}\text { Inhibition } \\
\text { Efficiency, \% }\end{array}$ \\
\hline Blank & 7.4 & - \\
200 & 2.1 & 71.4 \\
400 & 2.0 & 73.0 \\
600 & 1.9 & 74.3 \\
800 & 1.7 & 76.4 \\
\hline
\end{tabular}

\section{Electrochemical polarization studies}

The calculated electrochemical polarization parameters such as corrosion potential $\left(\mathrm{E}_{\text {corr }}\right)$, corrosion current $\left(\mathrm{I}_{\text {corr }}\right)$, anodic and cathodic Tafel slope $\left(\mathrm{b}_{\mathrm{a}}\right.$ and $\left.\mathrm{b}_{\mathrm{c}}\right)$ values and IE are given in Table 4. It was obvious from Figure 3 that Tafel curves are not shifted markedly to the corrosion potential for the optimum concentration $(800 \mathrm{ppm})$ of SCL extract. It indicates that the SCL extract works through mixed mode of inhibition. The $\mathrm{I}_{\text {corr }}$ value for the best concentration of SCL extract was decreased when compared to blank solution. This decrease in $I_{\text {corr }}$ is an indication of a decrease in corrosion reaction, since corrosion current is proportional to the magnitude of corrosion reaction. The $I_{\text {corr }}, b_{a}$ and $b_{c}$ values were changed upon the addition of SCL extract, which means the extract molecules are adsorbed both on the anodic and cathodic sites. This results in the inhibition of both anodic metal dissolution and cathodic hydrogen evolution reactions. 
Table 4. Electrochemical polarization parameters of carbon steel in $1 \mathrm{~N} \mathrm{HCl}$ in the absence and presence of the best concentration of SCL extract

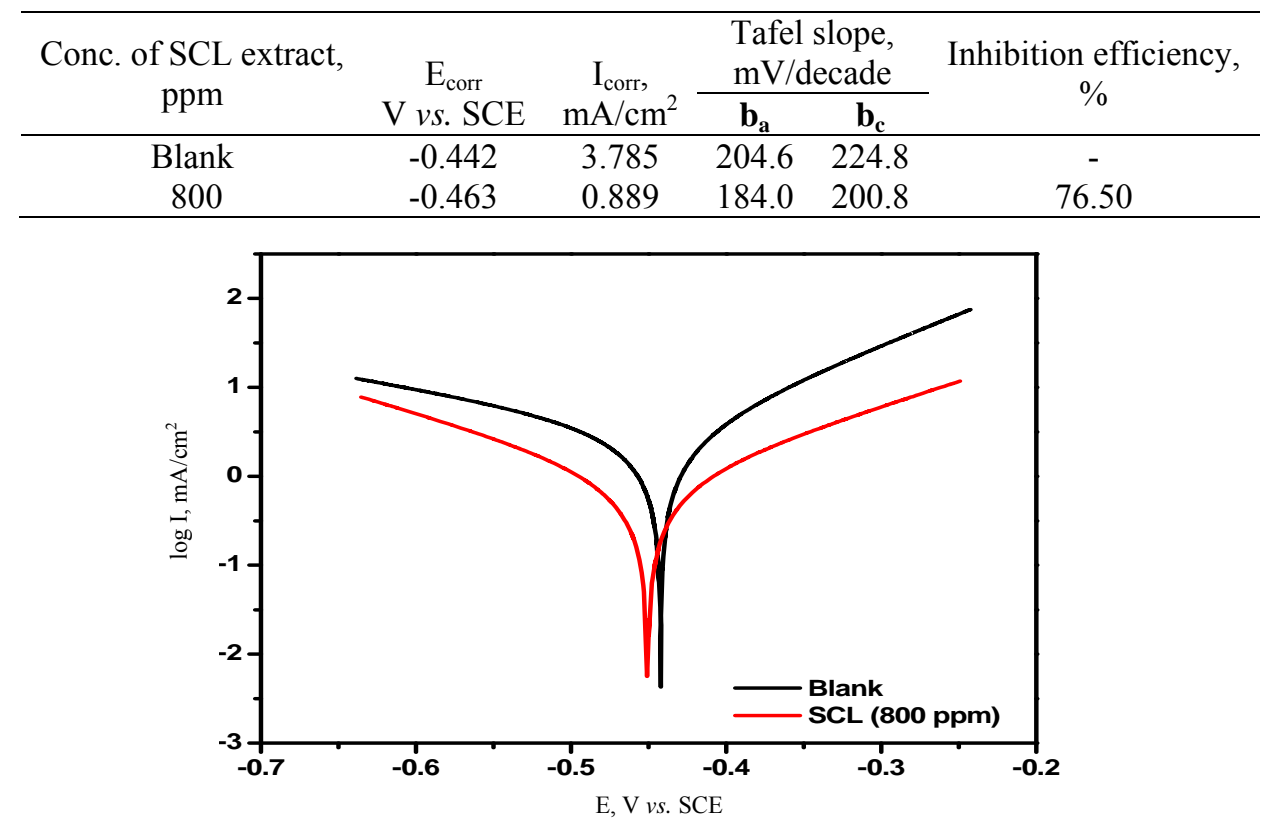

Figure 3. Electrochemical polarization curves of carbon steel in $1 \mathrm{~N} \mathrm{HCl}$ solution in the absence and presence of the best concentration of SCL extract

\section{AC- impedance studies}

The calculated impedance parameters such as double layer capacitance $\left(\mathrm{C}_{\mathrm{dl}}\right)$, charge transfer resistance $\left(\mathrm{R}_{\mathrm{t}}\right)$ and IE are listed in Table 5. It can be observed from the Nyquist plot (Figure 4) that a single semicircle has been observed is attributed to charge transfer takes place at an electrode/solution interface. It was apparent from the Table 5 that the presence of SCL extract in acid medium leads to decrease in $\mathrm{C}_{\mathrm{dl}}$. The decrease in $\mathrm{C}_{\mathrm{dl}}$ values can be attributed to the decrease in local dielectric constant and/or an increase in the thickness of electrical double layer. Meanwhile, the increase in $\mathrm{R}_{t}$ value indicates that the extent of adsorption increases in presence of the best concentration $(800 \mathrm{ppm})$ of SCL extract and also the adsorbed extract form a protective film on the carbon steel surface which becomes a barrier to hinder the mass and charge transfer processes. These results are an increase in the inhibition efficiency ${ }^{33}$. The maximum $\mathrm{R}_{\mathrm{t}}$ value of $83.58 \Omega \mathrm{cm}^{2}$ and the minimum $\mathrm{C}_{\mathrm{dl}}$ value of $28.49 \mu \mathrm{F} / \mathrm{cm}^{2}$ was obtained at the best concentration of $800 \mathrm{ppm}$ of the SCL extract, which gave the maximum inhibition efficiency of $75.35 \%$. This result has good concurrence with the results obtained from non-electrochemical methods.

Table 5. Impedance parameters for the corrosion of carbon steel in $1 \mathrm{~N} \mathrm{HCl}$ in the absence and presence of the best concentration of SCL extract at $30{ }^{\circ} \mathrm{C}$

\begin{tabular}{cccc}
\hline $\begin{array}{c}\text { Conc. of SCL } \\
\text { extract, ppm }\end{array}$ & $\begin{array}{c}\mathrm{R}_{\mathrm{t}}, \\
\Omega \mathrm{cm}^{2}\end{array}$ & $\begin{array}{c}\mathrm{C}_{\mathrm{dl}}, \\
\mu \mathrm{F} / \mathrm{cm}^{2}\end{array}$ & $\begin{array}{c}\text { Inhibition } \\
\text { Efficiency, \% }\end{array}$ \\
\hline Blank & 20.65 & 116.9 & - \\
800 & 83.58 & 28.49 & 75.35 \\
\hline
\end{tabular}




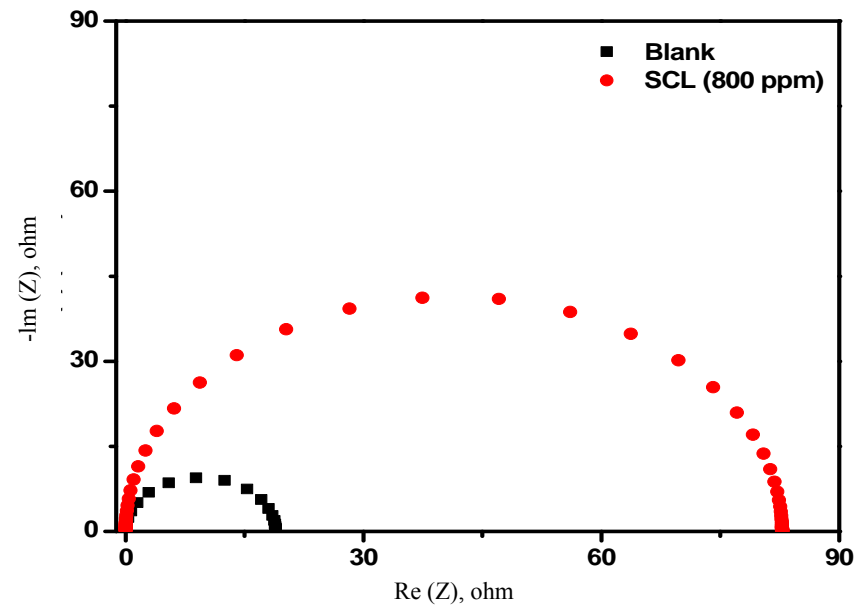

Figure 4. Impedance diagrams of carbon steel in $1 \mathrm{~N} \mathrm{HCl}$ solution in the absence and presence of the best concentration of SCL extract

\section{Effect of temperatures}

The influence of temperature on the corrosion behaviour of carbon steel in acidic medium was studied in the absence and presence of the SCL extract between $30{ }^{\circ} \mathrm{C}$ to $90{ }^{\circ} \mathrm{C}$ using weight loss measurements (Table 6). The corrosion rate of carbon steel increased with temperature both in the absence and presence of the SCL extract at the best concentration of $800 \mathrm{ppm}$. The presence of inhibitor leads to a decrease in the corrosion rate. The increase in corrosion rate was more pronounced with the rise of temperature. The inhibition efficiency was found to slightly decrease from $76.1 \%$ to $70.2 \%$ (Figure 5), when the temperature increased from $30{ }^{\circ} \mathrm{C}$ to $90{ }^{\circ} \mathrm{C}$. The reason for the decline in efficiency was due to the physical adsorption process occurred between the metal and the SCL extract.

Table 6. Corrosion of carbon steel in the absence and presence of the best concentration of SCL extract in $1 \mathrm{~N} \mathrm{HCl}$ at different temperatures obtained by weight loss method

\begin{tabular}{cccc}
\hline $\begin{array}{c}\text { Conc. of SCL extract, } \\
\text { in ppm }\end{array}$ & $\begin{array}{c}\text { Temperature, } \\
{ }^{\circ} \mathrm{C}\end{array}$ & $\begin{array}{c}\text { Corrosion rate, } \\
\text { mmpy }\end{array}$ & $\begin{array}{c}\text { Inhibition efficiency, } \\
\%\end{array}$ \\
\hline & 30 & 122.46 & - \\
Blank & 50 & 152.92 & - \\
& 70 & 189.46 & - \\
& 90 & 241.60 & - \\
800 & 30 & 29.19 & 76.1 \\
& 50 & 39.04 & 74.4 \\
& 70 & 51.78 & 72.6 \\
& 90 & 71.82 & 70.2 \\
\hline
\end{tabular}

\section{Mechanism of corrosion inhibition}

To elucidate the mechanism of inhibition, the Arrhenius plot employed in the absence and presence of the best concentration ( $800 \mathrm{ppm}$ ) of SCL extract in $1 \mathrm{~N} \mathrm{HCl}$ medium is shown in Figure 7. Arrhenius equation is as follows: 


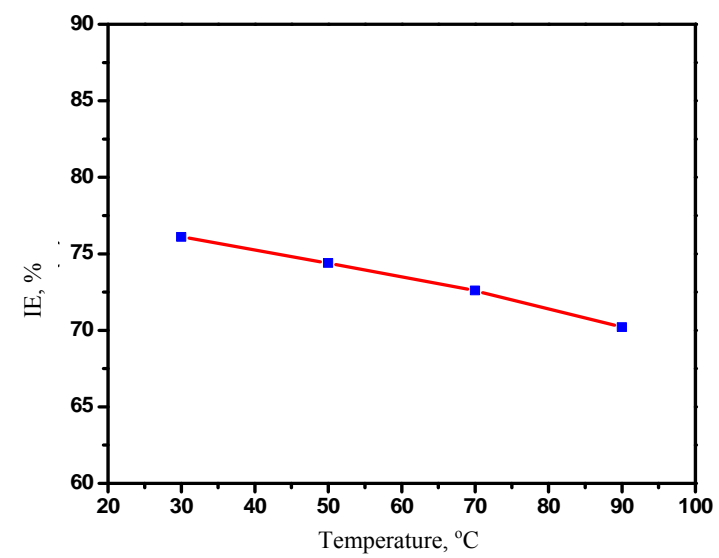

Figure 5. Effect of temperature on the corrosion inhibition efficiency of carbon steel in $1 \mathrm{~N}$ $\mathrm{HCl}$ solution in presence of the best concentration $(800 \mathrm{ppm})$ of SCL extract

$$
\ln r=A-\frac{E_{a}}{R T}
$$

Where $\mathrm{r}$ is the corrosion rate, $\mathrm{A}$ is the constant frequency factor, $\mathrm{E}_{\mathrm{a}}$ is the apparent activation energy and $\mathrm{R}$ is the gas constant. It showing a straight line according to the Arrhenius equation and revealing the effect of temperature. The calculated values of activation energy $\left(E_{a}\right)$, enthalpy of adsorption $(\Delta \mathrm{H})$, free energy of adsorption $\left(\Delta \mathrm{G}^{\circ}\right)$ and entropy of adsorption $(\Delta \mathrm{S})$ for carbon steel in the absence and presence of the best concentration of SCL extract in $1 \mathrm{~N} \mathrm{HCl}$ solution are shown in Table 7. The activation energy $\left(E_{a}\right)$ was found to be $12.58 \mathrm{~kJ} \mathrm{~mol}^{-1}$ for blank and increased to $16.93 \mathrm{~kJ} \mathrm{~mol}^{-1}$ in presence of the SCL extract in $1 \mathrm{~N} \mathrm{HCl} \mathrm{suggesting} \mathrm{that} \mathrm{the} \mathrm{adsorbed} \mathrm{organic} \mathrm{matter} \mathrm{creates} \mathrm{a} \mathrm{physical} \mathrm{barrier} \mathrm{to} \mathrm{charge} \mathrm{and}$ mass transfers, leading to reduction in corrosion rate. The higher value of Ea in presence of the SCL extract compared to that in the absence of the extract is due to physical adsorption ${ }^{34}$. The free energy of adsorption was calculated using the following equation:

$$
\Delta \mathrm{G}^{0}{ }_{\text {ads }}=-R T \ln (\mathrm{K} 55.5)
$$

where the value of 55.5 is the concentration of water in solution $\left(\mathrm{mol} \mathrm{L}^{-1}\right) . \mathrm{K}$ is the degree of surface coverage on the metal surface, $\mathrm{R}$ is the universal gas constant and $\mathrm{T}$ is the absolute temperature.

Adsorption process is caused by electrostatic attraction between charged metal surface and charged organic molecules.In this study, the $\Delta \mathrm{G}^{\circ}$ values are in the range of $-9.34 \mathrm{~kJ} \mathrm{~mol}^{-1}$ at $363 \mathrm{~K}$. As the values of free energy of adsorption are less than $-20 \mathrm{~kJ} \mathrm{~mol}^{-1}$, where the mode of inhibition is due to physisorption ${ }^{35}$. The negative sign of free energy of adsorption indicates that the adsorption of SCL extract on carbon steel surface is a spontaneous process. The major constituents present in SCL extract is alkaloids. These compounds adsorbed on the carbon steel surface made a barrier for charge and mass transfers leading to a decrease in the interaction of carbon steel with the corrosive environment. As a result, the corrosion rate of carbon steel decreased. The formation of film layer prevents the corrosion of carbon steel. The literature survey revealed that luteolin, quercetin and kaempferol are the principal alkaloids present in the leaves extract of Senna auriculata ${ }^{36}$. These alkaloids contain hydroxyl groups which show inhibition action of SCL extract (Figure 6). The inhibitor SCL extract adsorb over the carbon steel surface and forms a compact protective thin layer. 
<smiles>[R2]c1cc(-c2oc3cc(O)cc(O)c3c(=O)c2[R2])ccc1O</smiles>

$\mathrm{R}_{1}=\mathrm{H}, \mathrm{R}_{2}=\mathrm{OH}$; luteolin, $\mathrm{R}_{1}=\mathrm{R}_{2}=\mathrm{OH}$; quercetin, $\mathrm{R}_{1}=\mathrm{OH}, \mathrm{R}_{2}=\mathrm{H}$; Kaempferol

Figure 6. Structure of Luteolin, Quercetin and Kaempferol

The positive values of $\Delta H$ both in the absence and presence of SCL extract reflect the endothermic nature of the carbon steel corrosion process. It is also obvious that the activation energy supporting the proposed inhibition mechanism. Low and positive values of $\Delta \mathrm{S}$ entropies imply that the process was slow and the activated complex is the rate determining step represents an association rather than a dissociation step, meaning that a decrease in disordering takes place on going from reactants to the activated complex. Similar observation has been reported in the literature ${ }^{37}$.

Table 7. Calculated values of activation energy $\left(E_{a}\right)$, enthalpy of adsorption $(\Delta H)$, free energy of adsorption $\left(\Delta \mathrm{G}^{\circ}\right)$ and entropy of adsorption $(\Delta \mathrm{S})$ for carbon steel in the absence and presence of the best concentration of SCL extract in $1 \mathrm{~N} \mathrm{HCl}$ solution

\begin{tabular}{|c|c|c|c|c|c|}
\hline $\begin{array}{c}\text { Conc. of SCL } \\
\text { extract, ppm }\end{array}$ & $\begin{array}{c}\text { Temp. } \\
\text { K }\end{array}$ & $\begin{array}{c}\mathrm{E}_{\mathrm{a}} \\
\mathrm{kJ} \mathrm{mol}^{-1}\end{array}$ & $\begin{array}{c}\Delta \mathrm{G}^{\circ}, \\
\mathrm{kJmol}^{-1}\end{array}$ & $\begin{array}{c}\Delta \mathrm{H}, \\
\mathrm{kJmol}^{-1}\end{array}$ & $\begin{array}{c}\Delta \mathrm{S}, \\
\mathrm{kJmol}^{-1}\end{array}$ \\
\hline \multirow{3}{*}{ Blank } & 303 & - & - & - & - \\
\hline & 323 & 9.04 & - & 6.35 & - \\
\hline & 343 & 9.87 & - & 7.02 & - \\
\hline \multirow{5}{*}{800} & 363 & 12.58 & - & 9.56 & - \\
\hline & 303 & - & -7.80 & - & - \\
\hline & 323 & 11.83 & -8.31 & 9.14 & 0.054 \\
\hline & 343 & 13.00 & -8.83 & 10.15 & 0.055 \\
\hline & 363 & 16.93 & -9.34 & 13.91 & 0.064 \\
\hline \multicolumn{6}{|c|}{$\begin{array}{l}\text { Blank) } \\
\text { SCL (800 ppm) }\end{array}$} \\
\hline & & & & & \\
\hline & 2.8 & 3.0 & 3.2 & 3.5 & \\
\hline & & $1 / \mathrm{T} 1$ & & & \\
\hline
\end{tabular}

Figure 7. Arrhenius plots of carbon steel immersed in $1 \mathrm{~N} \mathrm{HCl}$ solution in the absence and presence of the best concentration $(800 \mathrm{ppm})$ of SCL extract 


\section{Adsorption isotherm}

Adsorption isotherm provides information regarding the interaction between the SCL extract and the carbon steel surface. The value of surface coverage $(\theta)$ has been obtained from weight loss measurements. The values of $\theta$ were fitted to different isotherms and Langmuir isotherm was found to be the best description behavior of adsorption for SCL extract. A plot of $\mathrm{C} / \theta$ versus $\mathrm{C}$ gives a straight line with a unit slope suggesting that the adsorption of SCL extract on the surface of carbon steel in $1 \mathrm{~N} \mathrm{HCl}$ solution follows Langmuir adsorption isotherm (Figure 8).

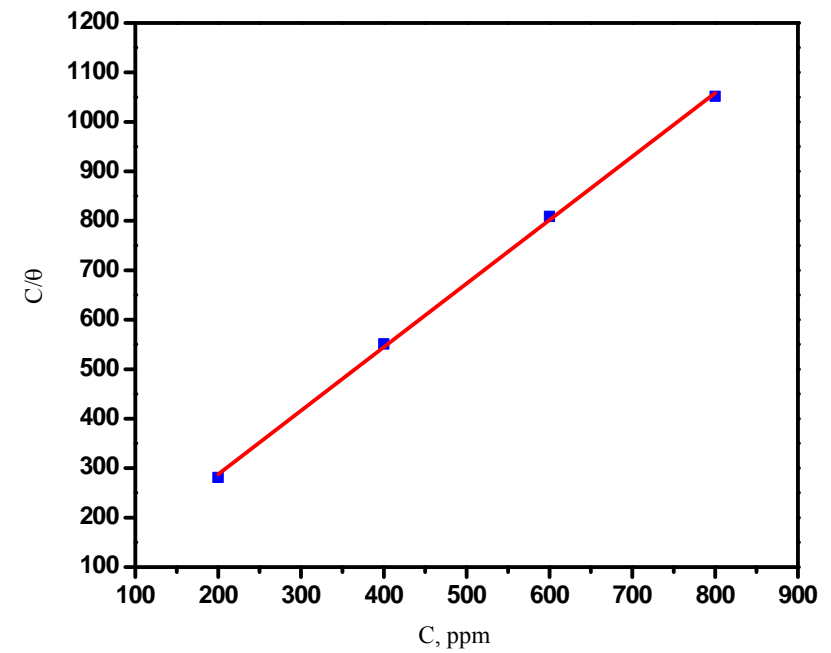

Figure 8. Langmuir adsorption isotherm plot for the adsorption of various concentrations of SCL extract on the surface of carbon steel in $1 \mathrm{~N} \mathrm{HCl}$ solution

\section{Surface morphological studies}

The surface morphology of the samples was studied by metallurgical microscope with the magnification of 1000x. The micrographs obtained for carbon steel immersed in $1 \mathrm{~N} \mathrm{HCl}$ solution without and with 800 ppm of SCL extract are shown in Figure 9 (a \& b). The results showed that the dissolution of carbon steel without inhibitor (Figure 9a) and the formation of smooth surface on carbon steel with SCL extract (Figure 9b).

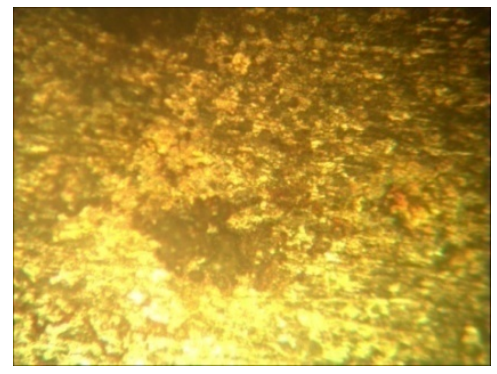

Figure 9(a). Metallurgical microscope image of carbon steel in $1 \mathrm{~N} \mathrm{HCl}$ solution (blank)

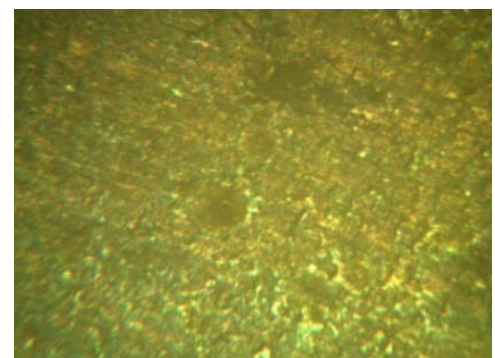

Figure 9(b). Metallurgical microscope image of carbon steel immersed in $1 \mathrm{~N} \mathrm{HCl}$ solution containing $800 \mathrm{ppm}$ of SCL extract 


\section{Conclusion}

The electrochemical polarization studies showed that the aqueous extract of SCL acts as a mixed inhibitor for carbon steel in $1 \mathrm{~N} \mathrm{HCl}$ solution. The inhibition efficiency increases with increase in concentration of SCL extract and decreases with temperature. The adsorption of the extract follows Langmuir adsorption isotherm. The percentage inhibition efficiency obtained from weigh loss measurements is comparable with those obtained from electrochemical measurements. The obtained thermodynamic parameters indicate that the adsorption of the SCL extract on carbon steel may be due to physisorption process. Surface morphological studies showed that the carbon steel in $1 \mathrm{~N} \mathrm{HCl}$ with the SCL extract was found smother than without the SCL extract.

\section{References}

1. Badr G E, Corros Sci., 2009, 51(11), 2529-2536; DOI:10.1016/j.corsci.2009.06.017

2. Aljourani J, Golozar M A and Raeissi K, Mater Chem Phys., 2010, 121(1-2), 320325; DOI:10.1016/j.matchemphys.2010.01.040

3. Ostovari A, Hoseinieh S M, Peikari M, Shadizadeh S R and Hashemi S J, Corros Sci., 2009, 51(9), 1935-1949; DOI:10.1016/j.corsci.2009.05.024

4. Shivakumar S S and Mohana K N, Adv Appl Sci Res., 2012, 3(5), 3097-3106.

5. Buchweishaija J, Tanz J Sci., 2009, 35, 77-92.

6. Al-Otaibi M S, Al-Mayouf A M, Khan M, Mousa A A, Al-Mazroa S A and Alkhathlan H Z, Arabian J Chem., 2014, 7(3), 340-346; DOI:10.1016/j.arabjc.2012.01.015

7. Halambek J, Berkovic K and Vorkapic'-Furac J, Corros Sci., 2010, 52(12), 39783983; DOI:10.1016/j.corsci.2010.08.012

8. Okafor P C, Ikpi M E, Uwah I E, Ebenso E E, Ekpe U J and Umoren S A, Corros. Sci., 2008, 50(8), 2310-2317; DOI:10.1016/j.corsci.2008.05.009

9. Okafor P C, Ebenso E E and Ekpe U J, Int J Electrochem Sci., 2010, 5, 978-993.

10. Oguzie E E, Corros. Sci., 2008, 50(11), 2993-2998; DOI:10.1016/j.corsci.2008.08.004

11. Oguzie E E, Enenebeaku C K, Akalezi C O, Okoro S C, Ayuk A A and Ejike E N, J Colloid Interf Sci., 2010, 349, 283-292; DOI:10.1016/j.jcis.2010.05.027

12. Vinod Kumar K P, Narayanan Pillai M S and Rexin Thusnavis G, Port Electrochim Acta, 2010, 28(6), 373-383; DOI:10.4152/pea.201006373

13. Loto C A, Corros Prevent Contr., 2001, 34 (2), 232-237.

14. Rajalakshmi R, Sathiyanarayana S, Marikkannu C and Sivakamasundari S, ISAEST VII, India, 2002, 142-145.

15. Prithiba A, Sathiyanarayana S, Rajalakshmi R and Sivakamasundari S, Proceedings of $11^{\text {th }}$ NCCI, Baroda, India, 2003, 3 .

16. Loto C A and Mohammed A I, Corros Prevent Contr., 2003, 50(3), 107-118.

17. Kalaiselvi Patchaiah, Chellammal Subbiah, Palanichamy Seeni and Subramanian Gopalan, Mater Chem Phys., 2010, 120(2-3), 643-648; DOI:10.1016/j.matchemphys.2009.12.015

18. Khalid Hasan S and Pinky Sisodia, Rasayan J Chem., 2011, 4(3), 548-553.

19. Sharmila A, Prema A A and Sahayaraj P A, Rasayan J Chem., 2010, 3(1), 74-81.

20. Cang Hui, Shi Wenyan, Lu Yu, Shao Jingling and Xu Qi, Asian J Chem., 2012, 24(12), 5625-5628.

21. Allaoui M, Cheriti A, Gherraf N, Chebouat E, Dadamoussa B and Salhi R, Int J Electrochem Sci., 2013, 8(7), 9429-9434. 
22. Sheeja V N and Subhashini S, Chem Sci Trans., 2014, 3(1), 129-140; DOI: $10.7598 /$ cst2014.656

23. Helen L Y S, Rahim A A, Saad B, Saleh M I and Bothi Raja P, Int J Electrochem Sci., 2014, 9(2), 830-846.

24. Anjaria J, Parabia M, Bhatt $G$ and Khamar R, Nature heal a glossary of selected indigenous medicinal plants of India ( $2^{\text {nd }}$ Ed. $)$, Ahmedabad: SRITI Innovations, 2002, 13, 1920.

25. Yesu Raj J, Paul John Peter M and Joy V, Asian J Plant Sci Res., 2012, 2(2), 187-192.

26. Usha Veerachari and Dr. Bopaiah A K, Int J Pharm Bio Sci., 2012, 3(2), 260-270.

27. Shivakumar S S, Mohana K N and Gurudatt D G, Chem Sci Trans., 2013, 2(1), 163 175; DOI:10.7598/cst2013.302

28. Sirajunnisa A, Fazal Mohamed M I, Subramania A and Venkatraman B R, IJSEAT., 2014, 2(1), 58-71.

29. Sureshkumar V, Venkatraman B R, Shobana V and Subramania A, Res J Chem Sci., 2012, 2(10), 87-94.

30. Subramania A, Sathiya Priya R, Saminathan K and Muralidharan V S, J Appl Electrochem., 2004, 34(7), 693-696; DOI:10.1023/B:JACH.0000031033.73171.f4

31. Gowrani T, Yamuna J, Parameswari K, Chitra S, Selvaraj A and Subramania A, AntiCorros Methods ater., 2004, 51(6), 414-419; DOI:10.1108/00035590410560967

32. Ehteram A Noor, J Appl Electrochem., 2009, 39, 1465-1475; DOI:10.1007/s10800009-9826-1

33. Lebrini M, Traisnel M, Lagrenee M, Mernari B and Bentiss F, Corros Sci., 2008, 50, 473-479; DOI:10.1016/j.corsci.2007.05.031

34. Lakshmi Prabha K, Shameela Rajam and Venkatraman B R, J Der Chemica Sinica, 2012, 3(1), 114-123.

35. Eduok U M, Umoren S A and Udoh A P, Arabian J Chem., 2012, 5(3), 325-337; DOI:10.1016/j.arabjc.2010.09.006

36. Malindra Juan-Badaturuge, Solomon Habtemariam and Michael J K Thomas Food Chemistry, 2011, 125(1), 221-225; DOI:10.1016/j.foodchem.2010.08.065

37. RosalineVimala J, Leema reose A and Raja S, Int J ChemTech Res., 2011, 3(4), 17911801. 